\title{
Student knowledge and perception before and after an orientation program in an offshore Caribbean medical school
}

\author{
Shankar PR, Dwivedi NR, Balasubramanium R, Dakubo GD \\ Xavier University School of Medicine, Aruba, Kingdom of the Netherlands
}

\begin{tabular}{ll}
\hline ARTICLE INFO \\
Received & $: 24 / 09 / 2014$ \\
Accepted & $: 07 / 01 / 2015$ \\
Published & $: 25 / 03 / 2015$
\end{tabular}

\section{KEYWORD}

Caribbean

Knowledge

Perception

Orientation program

\section{ABSTRACT}

Introduction: A two day orientation program is conducted for all first semester undergraduate medical students since January 2014. The effectiveness of the program and its possible impact on student knowledge and perceptions has not been previously studied. Objective: The present study was conducted to study student knowledge and perceptions before and after the orientation program and note differences in scores according to the gender and nationality of the respondents using a rretrospective-pre questionnaire. Method: The statements were scored and mean scores calculated. Student perception about the effectiveness of various sessions was also measured. Knowledge and perception scores before and after the program was compared using paired t-test. Strengths of the program and suggestions for further improvement were also obtained. Result: Nineteen of the twenty-five (76\%) first semester students participated. The mean knowledge and perception scores before the module were 1.97 (maximum score 3) and 2.75 (maximum score 5) respectively. After the program the knowledge and perception scores increased significantly to 2.75 and 4.41 . The mean overall effectiveness scores as perceived by the respondents was 3.16 (maximum score 4). Conclusion: The orientation program significantly improved knowledge and perception of students. The program was perceived as effective. Improvements are required in certain areas. Similar programs can be considered in other Caribbean medical schools.

(C) Medical Education Department, School of Medical Sciences, Universiti Sains Malaysia. All rights reserved.

CORRESPONDING AUTHOR: P Ravi Shankar, Xavier University School of Medicine, \#23, Santa Helenastraat, Aruba, Kingdom of the Netherlands. Email: ravi.dr.shankar@gmail.com

\section{Introduction}

Xavier University School of Medicine (XUSOM) is a private offshore Caribbean medical school in Aruba, Kingdom of the Netherlands admitting students from the United States (US), Canada and other countries to the undergraduate medical (MD) program. The school also offers a four semester premedical course to prepare high school students for admission to the MD course. The school shifted to an integrated organ system-based curriculum for the MD course from January 2013 [1]. Among the modifications to teaching-learning were use of standardized patients for learning and assessment, introduction of problem based learning, initiating a medical humanities module for all first semester MD students, providing early clinical exposure through visits to a local general practitioner and observer ship at the local general hospital, assessment of attitudes and behaviour, conducting sessions on critical appraisal of scientific literature (CASL), and teaching students to use essential medicines 
rationally. Initially the normal human subjects were taught during the first two semesters and the abnormal subjects were addressed during the third and fourth semesters. From January 2014 the school shifted to a fully integrated curriculum with the basic science subjects of anatomy, physiology, biochemistry, pathology, microbiology and pharmacology being covered as integrated, organ systems [2].

From the January 2014 semester a two day orientation program is offered to all first semester MD students. The program uses a mixture of didactic lectures and small group, activity based sessions to introduce students to the MD curriculum, discipline, professionalism, preparing for licensing exams, and the future of international medical graduates (IMGs) among other topics. Orientation programs and commencement addresses are common in medical schools. At a medical college in Hyderabad, India a three day orientation program addressing study skills, history of medicine, ethics and values, time management, communication skills and community health among other topics was conducted for first year students [3]. At KIST Medical College in Lalitpur, Nepal a week long orientation program is offered to all newly admitted first year undergraduate medical students [4]. Students' attitudes and knowledge was studied before and after the program. There was a significant increase in both knowledge and attitudes after the program.

The orientation program has been conducted for three intakes of students. The effectiveness of the program and its possible impact has not been previously studied. Hence the present study was carried out with the following objectives:

a. Measure knowledge and perceptions of students about selected areas before and after the orientation program

b. Compare the knowledge and perception scores among male and female students and students of different nationalities

c. Note student perceptions about the effectiveness of different sessions and

d. Obtain suggestions for further improvement.

\section{Method}

A two day orientation program is held for newly admitted first semester MD students of XUSOM during the second and third days of each semester. The program uses a mixture of interactive lectures, small group sessions and activities to introduce students to the MD program and the institution. Among the topics covered during the orientation program were basic information about the institution, the present status of the medical profession, the art of medicine, the MD curriculum, the United States health system, early clinical exposure, the future of international medical graduates (IMGs), preparing for the United States Medical Licensing Exam (USMLE) step 1, self-directed learning and team-based learning. Table 1 shows the schedule followed during the program (faal 2014).

Table 1: The orientation program at the institution

\begin{tabular}{|c|c|}
\hline Topic & Time \\
\hline \multicolumn{2}{|l|}{ Day 1} \\
\hline $\begin{array}{l}\text { Institutional educational } \\
\text { objectives }\end{array}$ & 8-8.30 am \\
\hline $\begin{array}{l}\text { What the future holds for } \\
\text { international medical graduates }\end{array}$ & $8.30-9 \mathrm{am}$ \\
\hline The XUSOM MD curriculum & 9-9.45 am \\
\hline The XUSOM Premed curriculum & $9.45-10 \mathrm{am}$ \\
\hline $\begin{array}{l}\text { Student discipline, behaviour and } \\
\text { professionalism }\end{array}$ & $10-10.45 \mathrm{am}$ \\
\hline Crossing the river & $11 \mathrm{am}-12 \mathrm{pm}$ \\
\hline $\begin{array}{l}\text { Learning in a team -an exciting } \\
\text { experience }\end{array}$ & $1: 00 p m-1: 45 \mathrm{pm}$ \\
\hline The art of medicine & $1.50-2.30 \mathrm{pm}$ \\
\hline Meet the experts & $2.40-3.30 \mathrm{pm}$ \\
\hline \multicolumn{2}{|l|}{ Day 2} \\
\hline $\begin{array}{l}\text { Preparing for self-directed } \\
\text { learning }\end{array}$ & $8-8.45 \mathrm{am}$ \\
\hline Preparing for USMLE step 1 & $9-9.45 \mathrm{am}$ \\
\hline The US Healthcare system & $10-10.45 \mathrm{am}$ \\
\hline Early clinical exposure & $11-11.45 \mathrm{am}$ \\
\hline Class notes & $1: 00-1: 30 \mathrm{pm}$ \\
\hline $\begin{array}{l}\text { Student assessment during the } \\
\text { MD program (basic sciences) }\end{array}$ & $1.30-2 \mathrm{pm}$ \\
\hline $\begin{array}{l}\text { Small group activity (problem } \\
\text { solving session) }\end{array}$ & $2-3.30 \mathrm{pm}$ \\
\hline
\end{tabular}

A retrospective-pre questionnaire was used to measure knowledge and perceptions of students about selected subject areas before and after the orientation program. The questionnaire used is 
shown in the Appendix. The knowledge was measured with reference to selected subject areas. For each subject area participants were asked whether they had no idea, have a vague idea or had a clear idea. 'No idea' was given the score 1, 'Have a vague idea' the score 2 and 'Clear idea' the score 3. Perceptions were measured by noting the respondents' agreement with a set of statements using a Likert type scale. The scoring system adopted was: 5 - strongly agree with the statement, 4 - agree, 3 - neutral, 2 - disagree and 1 - strongly disagree with the statement. Statements five to eight were negatively worded and their scores were reversed while computing the total perception scores. The mean knowledge and perceptions scores were calculated and compared among male and female respondents both before and after the module. The scores were also compared among students of different nationalities. Independent samples ttest was used for dichotomous variables and analysis of variance (ANOVA) for others. The mean scores before and after the module was compared using paired samples t-test. A p value less than 0.05 was taken as statistically significant.

The effectiveness of particular sessions was also noted. The effectiveness was noted according to the following scale: not effective was scored 1 , somewhat effective as 2 , effective as 3 and very effective as 4 . The mean effectiveness score for different topics and the total mean effectiveness scores were calculated. Participants were also asked to mention two strengths of the orientation program and two suggestions for further improvement. The suggestions were noted and common ones enumerated.

Written informed consent was obtained from all respondents. Respondents were informed that the study was voluntary and they had the option of not participating. The study was approved by the review board of the institution vide notification XUSOM/IRB/2014/05

\section{Result}

Nineteen of the twenty-five (76\%) first semester students enrolled during the Fall (September-
December) 2014 semester completed the questionnaire. Eight students (42.1\%) were male and 11 (57.9\%) were female. Six students (31.6\%) were of American (US) Nationality, 5 (26.3\%) were Canadian while seven (36.8\%) were of other nationalities. One respondent did not complete the information about nationality.

The mean knowledge and perception scores before the module were 1.97 (maximum score 3) and 2.75 (maximum score 5) respectively. After the orientation program the mean knowledge and perception scores increased significantly to 2.75 and 4.41. The knowledge scores after the orientation program were significantly higher among women (2.60 among men and 2.86 among women) $(\mathrm{p}=0.034)$. The mean overall effectiveness scores as perceived by the respondents was 3.16 (maximum score 4).

The mean perception scores before the module was 2.60 among men and 2.86 among women $(\mathrm{p}=0.034)$. Following the module the mean perception scores were higher among men (4.64) compared to women (4.24) but the difference was not significant. The mean perceived effectiveness scores of the sessions was 3.16 (maximum score 4). The mean effectiveness scores was slightly higher among women (3.20) compared to men (3.10). There was no significant difference in scores according to the nationality of the respondents. Table 2 shows the perceived mean effectiveness scores for different sessions.

The increase in knowledge and perception scores following the orientation program was highly significant $(\mathrm{p}<0.001)$. Among the strengths of the program were the program introduced us to the curriculum, assessment and PBL (3 respondents), the activity of 'Crossing the river' (3 respondents), many short sessions served to keep us focused ( 2 respondents), provided indication of future requirements to become a doctor (2 respondents), introduced us to early clinical exposure (2 respondents), and got to interact with our classmates (1 respondent). Among the suggestions for improvement were more group activities (4 respondents), reduce repetition of material between different sessions 
(3 respondents), address technical issues/problems which occurred occasionally (2

respondents) and certain sessions need to be more interactive (1 respondent).

Table 2 Respondents’ perceived effectiveness scores for different sessions.

\begin{tabular}{lc}
\hline Session & Perceived mean effectiveness scores \\
\hline Institutional educational objectives & 3.10 \\
What the future holds for international medical graduates & 3.10 \\
The XUSOM MD curriculum & 3.42 \\
Student discipline & 3.00 \\
Learning in a team & 3.47 \\
The art of medicine & 2.98 \\
Preparing for self-directed learning & 3.10 \\
Preparing for USMLE Step 1 & 3.31 \\
The US healthcare system & 2.78 \\
Early clinical exposure & 3.53 \\
Class Notes & 3.21 \\
Student assessment & 3.16 \\
Small group PBL session & 3.37 \\
\hline
\end{tabular}

\section{Discussion}

Like in a previous study [4] knowledge and perception scores in the areas studied significantly increased after the orientation program. Respondents' perceived effectiveness scores overall and regarding individual sessions was good. As stated previously the orientation program used interactive presentations and small group activity-based sessions to introduce students to the school curriculum, learning resources, the US healthcare system, licensing exams and faculty expectations from the students.

The duration of the program was short compared to the one conducted in a Nepalese medical school [4]. At XUSOM, Aruba a formal OP is a recent development and was first introduced for the Summer 2013 semester in May 2013. During the summer and fall 2013 semester a one day OP was conducted for the first semester MD and Premedical students. The program was extended to two days from January 2014 and small group activities to introduce students to each other, the faculty, small group work and to available resources for self-directed learning were conducted.
We are happy to note that student knowledge and perceptions about selected issues significantly improved following the program. This is similar to that observed in the study conducted in Nepal [4]. Student perception about the effectiveness of various sessions was also good. XUSOM has the mission of creating leaders in primary care who will improve health through patient care, education and research. The institutional goals concentrate on the science and practice of medicine, clinical competence, the social context of medicine, communication, professionalism, and lifelong learning. During the first session the Dean of Basic Sciences introduces the students to these objectives. These objectives are considered while designing the curriculum and planning assessments. During the second session, the chief academic officer introduces students to the present situation for international medical graduates (IMGs) in the US and Canadian healthcare systems and how students can maximize their chances of professional advancement.

XUSOM has shifted to a fully integrated MD curriculum from the January 2014 semester and all basic science subjects are taught together as integrated organ systems with early clinical exposure [5]. The basic science MD curriculum runs for six semesters of 15 weeks each with the 
last semester being devoted to preparing for the USMLE step 1 licensing exam. Crossing the river is an activity-based game where students in team cross a river full of dangerous reptiles using the 'magic boards' provided [6]. This is followed after the lunch break by a session which introduces students to learning in a team. Small group learning is widely used in the institution during PBL sessions, early clinical exposure, medical humanities sessions, clinicopathological correlation sessions and case presentations.

A medical humanities module is offered to all first semester MD students since January 2013 [7]. The module uses interactive presentations, case scenarios, paintings, debates and role-plays to explore different aspects of the medical humanities. Meet the experts is a session where each student is paired with a batch mate and introduces his/her partner to the larger group of students and faculty. Class notes is a server based system through which students access presentation material, syllabi, handbooks and guides and during the session the facilitators provide hands on demonstration of how to access and use the material. PBL occupies an important place in the institution though didactic lectures continue to be the predominant teaching-learning strategy. PBL sessions are conducted once a week and students perceived the small groups were effective [8]. Recently there has been increased emphasis on formative assessment and on assessment of student behaviour, professionalism and attitudes. I have briefly described the process of designing and conducting the two day orientation program in a recent article [9].

Certain sessions were delivered through Skype by school faculty based in the US. We are exploring using software which can be used to more effectively deliver the presentations. There were a few internet and connectivity problems during the presentation which was mentioned by the respondents in their suggestions for further improvement. Regarding introducing more group activities we are considering the suggestion but there may be difficulties in covering all the required topics and also conducting multiple small group activity-based sessions during a two day orientation program. The suggestions can be considered for implementation during future sessions.

Our study had limitations. The class size in the institution is small. Not all students participated in the study. So generalizability of the results of the present study to other settings may be limited. Student knowledge and perceptions were studied using a questionnaire and was not triangulated with data obtained from other sources. Knowledge and perception were studied immediately after the conclusion of the program using a retro-pre questionnaire.

Our experience with conducting an orientation program would be of special interest to educators in other Caribbean medical schools many of which have a semester of 15 weeks duration. A two day orientation program could be a good option for these schools and our topics and schedule could serve as a template for educators and program planners at these schools. The program schedule may also be useful for schools which offer a week long orientation program. Our schedule which concentrates on areas which we regard as absolutely essential can be expanded on by educators in these schools. The orientation program serves to introduce students to the school, the course of study and the faculty and will help students settle more easily into their course of study and help them be more effective learners. The retrospective-pre questionnaire used in this study which was modified from that used in the Nepalese study [4] (considering the orientation program offered at XUSOM) will be useful for other educators to evaluate their orientation programs. The questionnaire can be modified by other researchers as per specific requirements.

\section{Conclusion}

The orientation program was effective in significantly improving knowledge and perception of students about different subject areas. The program was perceived to be effective by the students. Improvements are required in certain areas and will be considered for future programs. As mentioned previously orientation 
programs are not common in Caribbean offshore medical schools and other medical educators in the Caribbean can consider developing an orientation program for students using a mixture of teaching-learning methods and concentrating on important 'must know' areas. Our experiences will also be of interest to educators in other regions.

\section{Reference}

1. Shankar P, Dubey AK. 'Modernizing' the Basic Sciences MD program at XUSOM, Aruba. WebmedCentral Medical Education 2013;4(4):WMC004198

2. Shankar PR, Bharti R, Ramireddy R, Balasubramanium R, Nuguri V. Students' perception of the learning environment at Xavier University School of Medicine, Aruba: a follow up study. J Educ Eval Health Prof. 2014:11:9

3. David MA. Foundational orientation program for medical students. Education in Medicine Journal 2013;5: e100.

4. Shankar PR, Karki BMS, Thapa TP, Singh N. Orientation program for first year undergraduate medical students: knowledge, attitudes and perceptions. Education in Medicine Journal 2012;4 (1).

5. Shankar PR, Bharti R, Ramireddy R, Balasubramanium R, Nuguri V. Students' perception of the learning environment at Xavier University School of Medicine, Aruba: a follow up study. J Educ Eval Health Prof. 2014;11:9

6. Shankar PR. Crossing the river! Education in Medicine Journal 2014;6(1):e74-e75.

7. Shankar PR. Medical humanities - initiating the journey@XUSOM. The literature, arts and medicine blog http://medhum.med.nyu.edu/blog/?p=4123. Posted on August 28, 2014.

8. Shankar PR, Nandy A, Balasubramanium R, Chakravarty S. Small group effectiveness during PBL sessions in a Caribbean medical school. J Educ Eval Health Prof. 2014;11:5.

9. Shankar PR. Designing and conducting a two day orientation program for first semester undergraduate medical students. J Educ Eval Health Prof. 2014:11:31.

\section{Appendix: Questionnaire used in the study}

Orientation Program for MD1 students - A Retrospective Pre

\begin{tabular}{|l|l|l|l|l|l|l|}
\hline \multirow{2}{*}{ Knowledge } & \multicolumn{2}{l|}{ At the conclusion of orientation program } & \multicolumn{2}{l|}{ Before the orientation program } \\
\cline { 2 - 6 } & No idea & Have a vague idea & Clear idea & No idea & Have a vague & Clear idea \\
\hline $\begin{array}{l}\text { Institutional educational } \\
\text { objectives }\end{array}$ & & & & & & \\
\hline What the future holds for IMGs & & & & & & \\
\hline The XUSOM MD curriculum & & & & & & \\
\hline Professionalism & & & & & & \\
\hline Learning in a team & & & & & & \\
\hline The art of medicine & & & & & & \\
\hline Self-directed learning & & & & & & \\
\hline The US healthcare system & & & & & & \\
\hline Early clinical exposure & & & & & \\
\hline
\end{tabular}




\begin{tabular}{|l|l|l|l|l|l|}
\hline Class Notes & & & & & \\
\hline Student assessment & & & & & \\
\end{tabular}

\begin{tabular}{|c|c|c|c|c|c|c|c|c|c|c|}
\hline \multirow[t]{2}{*}{ Perceptions } & \multicolumn{5}{|c|}{ At the conclusion of orientation program } & \multicolumn{5}{|c|}{ Before the orientation program } \\
\hline & $\begin{array}{l}\text { Strongly } \\
\text { Agree }\end{array}$ & Agree & $\begin{array}{l}\text { No } \\
\text { opinion }\end{array}$ & $\begin{array}{l}\text { Disagr } \\
\text { ee }\end{array}$ & $\begin{array}{l}\text { Strongly } \\
\text { disagree }\end{array}$ & $\begin{array}{l}\text { Strongly } \\
\text { Agree }\end{array}$ & Agree & $\begin{array}{l}\text { No } \\
\text { opinion }\end{array}$ & $\begin{array}{l}\text { Disagre } \\
\text { e }\end{array}$ & $\begin{array}{l}\text { Strongly } \\
\text { disagree }\end{array}$ \\
\hline $\begin{array}{l}\text { Being aware about the institutiona } \\
\text { will help me be a better student. }\end{array}$ & & & & & & & & & & \\
\hline $\begin{array}{l}\text { IMGs will have little problem in } \\
\text { integrating into the US/Canadian } \\
\text { healthcare system. }\end{array}$ & & & & & & & & & & \\
\hline $\begin{array}{l}\text { Learning in an integrated } \\
\text { curriculum will provide me with a } \\
\text { significant advantage. }\end{array}$ & & & & & & & & & & \\
\hline $\begin{array}{l}\text { Learning in a team makes learnin } \\
\text { more effective and long lasting. }\end{array}$ & & & & & & & & & & \\
\hline $\begin{array}{l}\text { I am not interested in knowing } \\
\text { about the art of medicine. }\end{array}$ & & & & & & & & & & \\
\hline $\begin{array}{l}\text { Self-directed learning is not } \\
\text { effective. }\end{array}$ & & & & & & & & & & \\
\hline $\begin{array}{l}\text { The US healthcare system } \\
\text { provides universal coverage. }\end{array}$ & & & & & & & & & & \\
\hline $\begin{array}{l}\text { Early clinical exposure is a waste } \\
\text { of time. }\end{array}$ & & & & & & & & & & \\
\hline $\begin{array}{l}\text { Formative student assessment is } \\
\text { important to assess attitudes \& } \\
\text { professionalism. }\end{array}$ & & & & & & & & & & \\
\hline
\end{tabular}

Effectiveness scores for different sessions:

\begin{tabular}{|l|l|l|l|l|}
\hline Session & Not effective & Somewhat effective & Effective & Very effective \\
\hline Institutional educational objectives & & & & \\
\hline What the future holds for IMGs & & & & \\
\hline The XUSOM MD Curriculum & & & & \\
\hline Student discipline & & & & \\
\hline Learning in a team & & & & \\
\hline The art of medicine & & & & \\
\hline Preparing for self-directed learning & & & & \\
\hline Preparing for USMLE Step 1 & & & & \\
\hline The US healthcare system & & & & \\
\hline Early clinical exposure & & & & \\
\hline Class Notes & & & & \\
\hline Student assessment & & & & \\
\hline Small group PBL session & & & & \\
\hline
\end{tabular}

